\title{
Staged Bilateral Nucleus Caudalis DREZ Lesioning for Persistent Idiopathic Facial Pain: Exceptional Case Report
}

\author{
Yucel KANPOLAT ${ }^{1}$, Eyyub S. M. AL-BEYATI ${ }^{1}$, Hakan YAKUPOGLU ${ }^{2}$ \\ ${ }^{1}$ Ankara University, School of Medicine, Department of Neurosurgery, Ankara, Turkey \\ ${ }^{2}$ Akay Hospital, Neurosurgery Clinic, Ankara, Turkey
}

\section{ABSTRACT}

Persistent idiopathic facial pain (PIFP) is a rare but challenging type of facial pain. How to manipulate such a problem becomes more contentious in cases with bilateral complaints. In situations when conventional treatments fail to reduce the pain, some treatment options like nucleus caudalis dorsal root entry zone (DREZ) lesioning shine as valuable means of managing such intractable problems. Herein, we report an individual with bilateral PIFP in which the patient suffered from intractable pain and was the first to undergo bilateral nucleus caudalis DREZ operation for PIFP. The patient was followed up and the procedure resulted in immediate and complete pain relief.

KEYWORDS: Facial pain, Persistent pain, DREZ, Nucleus caudalis

\section{INTRODUCTION}

$\mathrm{P}$ ersistent idiopathic facial pain (PIFP), previously designated as atypical facial pain, is a rare but challenging type of facial pain that does not have the characteristics of the cranial neuralgias and is not attributed to other disorders $(16,24)$. As was defined by the International Association for the Study of Pain and International Headache Society, PIFP occurs daily and persists for all or most of the day, is limited to an area on one side of face but is deep and poorly localized, is not associated with sensory loss or other neurological deficits, and persists without any demonstrable local cause $(16,24)$.

The recommended treatment for PIFP is generally tricyclic antidepressants and selective serotonin and norepinephrine reuptake inhibitors (37). In some cases or over time, pharmacological and noninvasive treatments fail to reduce the pain or the treatment itself ignores its efficacy considering the side effects. In these situations, some treatment options like tractotomy-nucleotomy and nucleus caudalis dorsal root entry zone (DREZ) lesioning shine as valuable means of managing such intractable problems $(19,43)$.
We report herein an individual with bilateral PIFP, rare in its nature, in which the patient suffered from intractable pain on her right side after being followed for more than nine years with a similar pain on the left side. She had been treated previously for the left-sided pain with nucleus caudalis DREZ lesioning, resulting in complete relief. For the newly formed right-sided pain, no satisfactory outcome could be achieved with all procedures and medications provided, and she was finally treated with nucleus caudalis DREZ lesioning, with immediate and complete pain relief.

\section{CASE REPORT}

\section{History and Presentation}

A 41-year-old woman who had been followed by the senior author (YK) with the diagnosis of left PIFP, complained of persistent intractable pain on the right side of her face that had increased gradually in terms of severity and intensity over the past nine months. The pain was described as piercing, throbbing and stabbing, with distribution to the ipsilateral side of the neck and occipital region. The pain was accompanied 
by diplopia, ipsilateral miosis, eye redness with minimal discharge, and nausea with occasional vomiting. The patient had ipsilateral numbness, tingling and weakness in her neck, shoulder, arm, and hand, and facial allodynia was also present. The magnetic resonance imaging (MRI) revealed no significant vascular compression or intracranial abnormalities. Her Visual Analogue Scale (VAS) score was 9.8.

Before the initiation of her complaints, she had experienced some psychological deterioration but the psychiatric consultations revealed no proven problems. The electroencephalogram demonstrated no abnormalities. Duloxetine was effective at first, but her pain severity increased gradually. Her medications included Duloxetine (CYMBALTA ${ }^{\circledR}, 30 \mathrm{mg}, 2 \times 1$ ), a combination of paracetamol, caffeine and codeine phosphate (GERALGINE-K ${ }^{\circledR}, 2 \times 1$ ) and later, 2 doses daily of intravenous morphine sulfate, in the last two months. The pain responded mildly to oxygen supplementation. The pain was severe enough to prevent her from conducting daily activities and rendered her completely incapacitated. She stated her intent to commit suicide due to the intractable persistent pain and her deteriorated life quality.

Her medical history revealed onset of a similar pain on her left side 12 years before. She had been followed and treated by another team with the diagnosis of migraine with aura and cluster headache. No single or combination therapy of analgesics or interventional therapies provided satisfactory pain relief. Later, she was referred to the senior author and was diagnosed with PIFP. After a follow-up period of six months with medications, a left-sided computed tomography (CT)-guided trigeminal tractotomy-nucleotomy (TR-NC) procedure was achieved with complete pain relief. Twenty-three months later, the same pain relapsed after a blunt facial trauma. A second left TR-NC procedure was performed with partial pain control. Pain intensity increased in eight months, and the patient was finally treated by the senior author with left nucleus caudalis DREZ lesioning, with complete pain relief over 80 months of follow-up.

\section{Operation}

During preparation, an MRI scan was obtained in order to measure the diameters of the brainstem for the electrode arrangement (29). The patient's head was fixed with the Mayfield headholder and she was placed in the sitting position under general anesthesia. Preoperative corticoid (methylprednisolone) and intravenous (IV) antibiotic were administered. Neuromonitoring, stimulating and recording needle electrodes were placed on the skin. The incision was started at the midline just at the external occipital protuberance and extended below the spinous process of $\mathrm{C} 2$. Lamina and spinous process of $\mathrm{C} 1$ and left lamina of $\mathrm{C} 2$ were absent because of the previous operation on the left side; thus, the laminectomy of $\mathrm{C} 2$ was extended and the spinous process of $\mathrm{C} 2$ was removed with total laminectomy. Baseline evoked responses were measured 1 hour after induction from the right and left musculus trapezius, deltoideus, extensor digitorum communis, abductor pollicis brevis, and abductor hallucis, at 350 microvolts (mV). The dura was incised in a Y-shaped configuration using a surgical microscope, and the arachnoid was then opened. After a careful dissection and viewing of the important landmarks
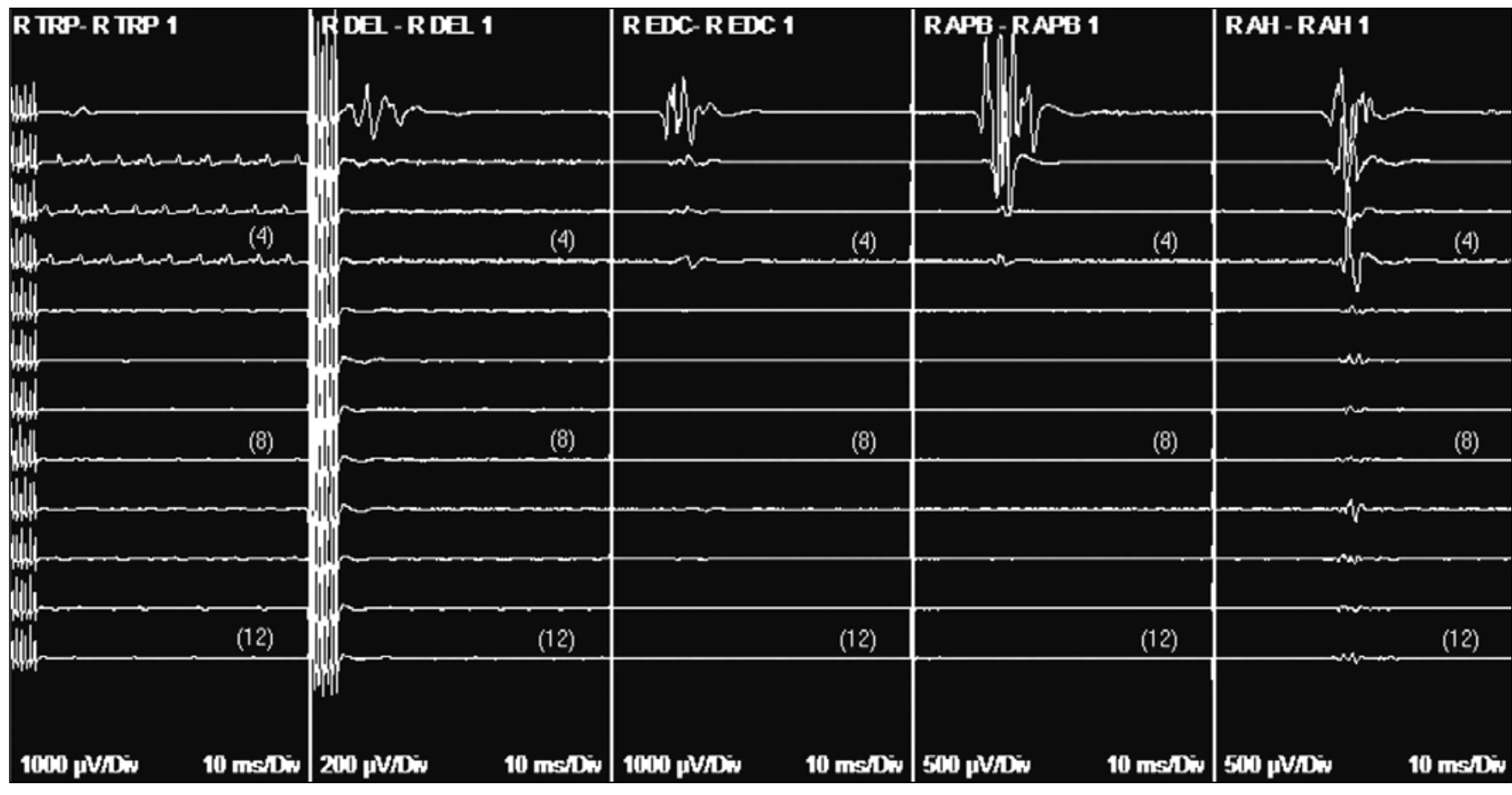

Figure 1: Motor-evoked potentials on the right at the different study recording periods. The five segments shown in the figure belong to measurements from the musculus trapezius (TRP), deltoideus (DEL), extensor digitorum communis (EDC), abductor pollicis brevis (APB), and abductor hallucis $(\mathrm{AH})$. 
such the obex, rootlets, sulcus intermediolateralis, and cranial roots of the accessory nerve, DREZ lesions were made using the El-Naggar-Nashold nucleus caudalis DREZ electrodes (3 $\mathrm{mm}$ in length, $0.25 \mathrm{~mm}$ in diameter). Lesions were created just above the sensory rootlets of the $\mathrm{C} 2$ within the intermediolateral sulcus immediately above the obex behind the cranial roots of the accessory nerve. Fifteen standard radiofrequency (RF) lesions were made $\left(70^{\circ} \mathrm{C}, 15\right.$ seconds for each lesion). Intraoperative electromyography (EMG) and motor-evoked potentials (MEP) were obtained by experienced staff after each three-four lesions to alert surgeons to possible permanent injury, providing more selectivity and controllability. There was no change regarding the MEPs on the left, but changes were observed during the last three lesions on the right while ascending the spinal cord. The baseline MEPs values on the right for the deltoideus, extensor digitorum communis, abductor pollicis brevis, and abductor hallucis were 128.32 $\mathrm{mV}, 839.16 \mathrm{mV}, 907.08 \mathrm{mV}$, and $365.04 \mathrm{mV}$, respectively. All the measures were stable until the last three lesions, when the mentioned potentials were measured as $0 \mathrm{mV}, 243.36 \mathrm{mV}$, $110.62 \mathrm{mV}$ and $110.62 \mathrm{mV}$, respectively. After approximately 5 minutes, the second and third parameters were measured as $0 \mathrm{mV}$. No additional lesions were made above $\mathrm{C} 1$ rootlets level. Finally, the dura was sutured watertight with atraumatic silk, and closure was completed in order of anatomic layers.

\section{Postoperative Course}

The patient was observed in the intensive care unit for one day postoperatively. She was evaluated primarily regarding pain status and neurological functions. She was pain-free immediately with normal corneal sensation and no major limb dysfunction. On the second day, she was transferred to the general ward. Her VAS score for facial pain was 0 . A mild ipsilateral upper limb ataxia and dysmetria were observed accompanying mild ipsilateral lower extremity ataxia, but she was able to walk with minimal support. On the $5^{\text {th }}$ day, she was discharged and referred to a physical therapy center. The next day she was admitted with complaints of (pre) syncope, deteriorated consciousness, excessive sweating, treble, and nausea. On examination, she was neurologically stabile but hypotensive and bradycardic. The incision line was clean in terms of redness, discharge or any signs of infection. Her situation was regarded as opiate withdrawal. She was hospitalized, her vital parameters were monitored, and two diminished doses daily of morphine sulfate were administered. Her situation improved gradually and she was discharged on the $6^{\text {th }}$ day. She had minimal ipsilateral ataxia, which improved with physical therapy. She has been followed for 13 months and still has complete pain relief without any motor or sensation problems.

\section{- DISCUSSION}

History of the development of DREZ lesioning dates back to the 1930s, when Sjoqvist used intramedullary tractotomy to relieve facial pain and spare the touch sensation pathways (43). In 1968, Loeser et al. reported the possibility of an association between neuropathic pain and hyperactivity of dorsal horn neurons in the human spinal cord (21). Later, Schvarcz reported the functional similarity between the substantia gelatinosa of the spinal cord and the trigeminal nucleus caudalis of the cervicomedullary junction (38). The main principal of DREZotomy is based on destroying the mentioned hyperactive neurons of the dorsal horn and the excitatory portion of Lissauer's tract (39). DREZ microcoagulation was performed first by Nashold and Ostdahl for brachial plexus avulsion pain (30). It was the Bernard-Nashold group that first described the nucleus caudalis DREZ procedure (3). Different techniques, including microsurgical, RF, ultrasonic, and laser ablation, have been used to perform DREZ lesioning $(7,10$, $30,39,40,45)$. Later, in 2008 , the senior author (YK) innovated a CT-guided percutaneous technique to perform nucleotomy (18).

Management of PIFP is a challenging problem even from the diagnosis phase in terms of definition and classification. The prevalence of orofacial pain was reported to range between $15-25 \%$, and $10 \%$ of patients have chronic pain $(20,22,34)$. Up to $30 \%$ of orofacial pain cannot be classified (46). PIFP crosses to the other side at a rate of $35 \%(13,33,35)$. The subjective nature of the pain, with no confirmatory laboratory test or imaging technique, renders the problem more complex for both the patient and physician and makes vital an effective communication. Treatment options, even multiple, may be disappointing to the patient when they fail to provide relief. It is also well recognized that no single treatment option will address all patients' problems (9).

Chronic pain is highly associated with depression due to its enduring burden $(2,32)$. It was reported that $95 \%$ of patients with PIFP complain of other symptoms like headache, neck and backache, and other systemic complaints (12). Madland et al. recommended evaluating patients regarding their disability in terms of psychological discomfort and psychological and social disability rather than confining the evaluation to pain intensity alone (23). The patient presented herein expressed a suicidal intent if the DREZ lesioning operation was not made available to her as an opportunity for cure. This reflects her satisfaction following the first left-sided nucleus caudalis DREZ operation and also the untreatable and intense nature of her disability on the right side.

The main issue regarding PIFP is the lack of a consensus regarding the treatment strategy and patient manipulation. Also how to manipulate such a problem becomes more contentious in cases with bilateral complaints. A multidisciplinary evaluation is essential for this population (11). Even controversial, recommended analgesics and other pain modulators may fail to achieve pain relief. Neurosurgical procedures like nucleus caudalis DREZ lesioning should be considered as valuable options when the classic treatments fail to reduce pain. There are reports in the literature of response to nucleus caudalis DREZ lesioning in the treatment of anesthesia dolorosa, postherpetic neuralgia, cerebral infarction, PIFP, multiple sclerosis, pain secondary to head trauma, craniofacial surgery, and neoplasm $(3-5,14,25,26,28,29)$. Gorecki et al. (14) reported limited response to the operation among PIFP patients and a small number of patients that maintained their pain-free status in the long-term. Nashold et al. reported that less than one- 
fourth of patients remained pain-free one year after the operation $(14,27)$. Sindou et al. concluded that paroxysmal shooting pain was significantly more responsive to the procedure than pain described as a continuous burning sensation $(41,42)$. The literature reports a pain reduction that varies between $50 \%$ and $87 \%$ after DREZ lesioning for brachial plexus injury $(6,36$, 42). Awad et al. (1) reported that $84 \%$ of their patients sought to undergo repeat DREZ lesioning when it was presented as a choice. In our reported case, a pain-free status of 80 months was achieved on the left, the formerly operated side, which seems to be beyond the reported pain-free survival range. In our previously reported series, $69 \%$ of patients reported satisfactory pain relief one year after DREZ lesioning (19). Furthermore, in two of our patients who were diagnosed with complex regional pain syndrome type $\mathrm{I}$, a pain syndrome with no reported curative treatment, the DREZ operation was curative in one (71 months' follow-up) and provided satisfactory results in the other (44 months' follow-up) (17).

DREZ lesions in general are not expected to affect sensation to touch or trigeminal motor function, but ataxia, usually transient, was found to be the most common complication (14). Maximum attention should be given in cases with bilateral facial pain. Determining the real necessity for an additional lesioning to the other side and evaluating all other treatment options are essential. Delgado-López et al. (8) found that using a midline approach, preoperative steroids, a third-generation electrode, double-row coagulations, and sufficient rostral extension to be crucial for improved results. Intraoperative neuromonitoring is becoming the standard of care in many spinal surgeries. Intraoperative studies have shown that changes in MEPs correlate strongly with postoperative neurological status $(31,44)$. Usage of neurophysiological monitoring technologies may help the surgeon to locate and identify the targets as well as possible variant anatomy, thus avoiding such complications (15).

\section{CONCLUSION}

To our knowledge, the case reported herein is the first to undergo bilateral nucleus caudalis DREZ operation for PIFP. A multidisciplinary approach paying maximum attention to identifying and diagnosing pain syndromes correctly and in a timely manner is essential for satisfactory results when addressing such problems. The nucleus caudalis DREZ lesioning operation should be considered as a last but potentially curative treatment option in incapacitated cases that show poor or no response to the other treatment alternatives.

\section{- REFERENCES}

1. Awad AJ, Forbes JA, Jermakowicz W, Eli IM, Blumenkopf B, Konrad P: Experience with 25 years of dorsal root entry zone lesioning at a single institution. Surg Neurol Int 4:64, 2013

2. Bair MJ, Robinson RL, Katon W, Kroenke K: Depression and pain comorbidity: A literature review. Arch Intern Med 163:2433-2445, 2003

3. Bernard EJ, Nashold BS, Caputi F, Moossy JJ: Nucleus caudalis DREZ for facial pain. Br J Neurosurg 1:81-92, 1987
4. Broggi G, Dones L, Ferroli R, Franzini A, Pluderi M: Le róle de la thalamotomie, de la cordotomie et de la lésion de la "dorsal root entry zone" (DREZ) caudalis trigeminalis dans le traitement de la douleur chronique. Neurochirurgie 46:447453, 2000

5. Bullard DE, Nashold BS: The caudalis DREZ for facial pain Stereotact Funct Neurosurg 68:168-174, 1997

6. Chen HJ, Tu YK: Long term follow-up results of dorsal root entry zone lesions for intractable pain after brachial plexus avulsion injuries. Acta Neurochir Suppl 99:73-75, 2006

7. Chun H-J, Kim YS, Yi H-J: A modified microsurgical DREZotomy procedure for refractory neuropathic pain. World Neurosurg 75(3-4):551-557, 2011

8. Delgado-López P, García-Salazar F, Mateo-Sierra O, CarrilloYagüe R, Llauradó G, López E: Trigeminal nucleus caudalis dorsal root entry zone radiofrequency thermocoagulation for invalidating facial pain. Neurocirugia (Astur) 14(1):25-32, 2003

9. Dionne RA: Pharmacologic advances in orofacial pain: From molecules to medicine. J Dent Educ 65(12):1393-1403, 2001

10. Dreval ON: Ultrasonic DREZ-operations for treatment of pain due to brachial plexus avulsion. Acta Neurochir 122:76-81, 1993

11. Elias WJ, Burchiel KJ: Trigeminal neuralgia and other neuropathic pain syndromes of the head and face. Curr Pain Headache Rep 6(2):115-124, 2002

12. Feinmann C: The long-term outcome of facial pain treatment. J Psychosom Res 37:381-387, 1993

13. Giller C: Atypical facial pain and anesthesia dolorosa. In: Burchiel K (ed), Surgical Management of Pain. New York: Thieme, 2002:311-316

14. Gorecki JP, Nashold BS, Rubin L, Ovelmen-Levitt J: The Duke experience with nucleus caudalis DREZ coagulation. Stereotact Funct Neurosurg 65:111-116, 1995

15. Husain AM, Elliott SL, Gorecki JP: Neurophysiological monitoring for the nucleus caudalis dorsal root entry zone operation. Neurosurg 50(4):822-827, 2002

16. International Classification of Headache Disorders, 2nd ed. Cephalalgia 24 Suppl 1:126-136, 2004

17. Kanpolat Y, Al-Beyati ES, Ugur HC, Akpinar G, Kahilogullari G, Bozkurt M: A curative treatment option for complex regional pain syndrome (CRPS) type I: Dorsal root entry zone operation (report of two cases). Turk Neurosurg 24(1):127-130, 2014

18. Kanpolat $Y$, Kahilogullari G, Ugur HC, Elhan AH: Computed tomography-guided percutaneous trigeminal tractotomynucleotomy. Neurosurgery 63 Suppl 1:ONS147-153, 2008

19. Kanpolat Y, Tuna H, Bozkurt M, Elhan AH: Spinal and nucleus caudalis dorsal root entry zone operations for chronic pain. Neurosurgery 62(3) Suppl 1:235-242, 2008

20. Lipton JA, Ship JA, Larach-Robinson D: Estimated prevalence and distribution of reported orofacial pain in the United States. J Am Dent Assoc 124(10):115-121, 1993

21. Loeser JD, Ward AA, White LE: Chronic deafferentation of human spinal cord neurons. J Neurosurg 29:48-50, 1968

22. Macfarlane TV, Blinkhorn AS, Davies RM, Kincey J, Worthington HV: Oro-facial pain in the community: Prevalence and associated impact. Community Dent Oral Epidemiol 30(1):52-60, 2002 
Kanpolat Y. et al: Bilateral Nucleus Caudalis DREZ Lesioning

23. Madland G, Feinmann C, Newman S: Factors associated with anxiety and depression facial arthromyalgia. Pain 84:225-232, 2000

24. Merskey H, Bogduk N: Relatively localized syndromes of the head and neck. In: Merskey H, Bogduk N (eds), Classification of Chronic Pain, 2nd ed. Seattle: IASP Press, 1994:59-60

25. Mertens $P$, Sindou M: Chirurgie au niveau de la zone d'entrée des racines dorsales dans la moelle (dorsal root entry zone) pour le traitement des douleurs chroniques. Neurochirurgie 46:429-446, 2000

26. Meyerson BA: Neurosurgical approaches to pain treatment. Acta Anaesthesiol Scand 45:1108-1113, 2001

27. Nashold BS, El-Naggar A, Abdulhak MM, Ovelmen-Levitt J, Cosman E: Trigeminal nucleus caudalis dorsal root entry zone: A new surgical approach. Stereotact Func Neurosurg 59:4551, 1992

28. Nashold BS, El-Naggar AO, Ovelmen-Levitt J, Abdul-Hak M: A new design of radiofrequency lesion electrodes for use in the caudalis nucleus DREZ operation. J Neurosurg 80:11161120, 1994

29. Nashold BS Jr, El-Naggar AO: Dorsal root entry zone (DREZ) lesioning. In: Rengachary SS, Wilkins RH (eds), Neurosurgical Operative Atlas. Baltimore: Williams \& Wilkins, 1992:9-24

30. Nashold BS Jr, Ostdahl RH: Dorsal root entry zone lesions for pain relief. J Neurosurg 51(1):59-69, 1979

31. Owen JH, Bridwell KH, Grubb R, Jenny A, Allen B, Padberg AM, Shimon SM: The clinical application of neurogenic motor evoked potentials to monitor spinal cord function during surgery. Spine 16 Suppl 8:385-390, 1991

32. Poleshuck EL, Bair MJ, Kroenke K, Damush TM, Tu W, Wu $\mathrm{J}$ : Psychosocial stress and anxiety in musculoskeletal pain patients with and without depression. Gen Hosp Psychiatry 31:116-122, 2009

33. Prestor B: Microsurgical junctional DREZ coagulation for treatment of deafferentation pain syndromes Surg Neurol 56:259-265, 2001

34. Riley JL 3rd, Gilbert GH, Heft MW: Orofacial pain symptom prevalence: Selective sex differences in the elderly? Pain 76(1-2):97-104, 1998
35. Sachs E Jr: The role of the nervus intermedius in facial neuralgia. J Neurosurg 28:54-60, 1968

36. Samii M, Bear-Henney S, Ludemann W, Tatagiba M, Blomer $\mathrm{U}$ : Treatment of refractory pain after brachial plexus avulsion with dorsal root entry zone lesions. Neurosurg 48:1269-1277, 2001

37. Sardella A, Demarosi F, Barbieri C, Lodi G: An up-to-date view on persistent idiopathic facial pain. Minerva Stomatol 58(6):289-299, 2009

38. Schvarcz JR: Spinal cord stereotactic techniques re trigeminal nucleotomy and extralemniscal myelotomy. Appl Neurophysiol 41:99-112, 1978

39. Sindou M, Daher A: Spinal cord ablation procedures for pain. In: Dubner R (ed). Proceedings of the Vth World Congress on Pain, Pain Research and Clinical Management. Amsterdam: Elsevier, 1988:477-495

40. Sindou M, Jeanmonod D: Microsurgical DREZ-otomy for the treatment of spasticity and pain in the lower limbs. Neurosurg 24:655-670, 1989

41. Sindou M, Mertens P, Wael M: Microsurgical DREZotomy for pain due to spinal cord and/or cauda equina injuries: Longterm results in a series of 44 patients. Pain 92:159-171, 2001

42. Sindou MP, Blondet E, Emery E, Mertens P: Microsurgical lesioning in the dorsal root entry zone for pain due to brachial plexus avulsion: A prospective series of 55 patients. J Neurosurg 102:1018-1028, 2005

43. Sjoqvist O: Studies on pain conduction in the trigeminal nerve: A contribution to the surgical treatment of facial pain. Acta Psychiatr Neurol Scand 17 Suppl:1-139, 1938

44. Sueda T, Okada K, Watari M, Orihashi K, Shikata H, Matsuura Y: Evaluation of motor- and sensory-evoked potentials for spinal cord monitoring during thoracoabdominal aortic aneurysm surgery. Jpn J Thorac Cardiovasc Surg 48:60-65, 2000

45. Young RF: Clinical experience with radiofrequency and laser DREZ lesions. J Neurosurg 72:715-720, 1990

46. Zebenholzer K, Wöber C, Vigl M, Wessely P, Wöber-Bingöl C: Facial pain and the second edition of the International Classification of Headache Disorders. Headache 46(2):259263, 2006 